\title{
A BUSCA PELA SOBERANIA MUNDIAL
}

Fabíola Soares de Melo

Universidade do Oeste Paulista - UNOESTE, Curso de Direito, Presidente Prudente/SP. E-mail: fabiola.fah.melo@hotmail.com

\section{RESUMO}

O objetivo deste estudo foi a compreensão do que significa soberania, não sendo apenas uma palavra em um texto jurídico, e sim um poder, um caminho de alcançar a igualdade mundial, pois se existisse a eficácia desta, haveria também um equilíbrio entre países desenvolvidos e os que ainda estão buscando este desenvolvimento, apontando principalmente que há grandes potências que tentam impor suas vontades podendo ocorrer conflitos, e quando há esses conflitos o que pode ser feito para saná-los, principalmente porque, devido ao poder militar e tecnologias existentes atualmente, guerras podem significar grandes consequências para a vida em nosso planeta, por este motivo deve-se buscar soluções no âmbito jurídico.

Palavras-chave: soberania, poder, eficácia, equilíbrio, conflitos.

\section{THE QUEST FOR GLOBAL SOVEREIGNTH}

\begin{abstract}
The aim of this study was to understand the meaning of sovereignty, not just a word in a legal text, but a power, a way to achieve global balance, for if there was its effectiveness, there would also be a equilibry between developed and those who are still searching for such development, pointing out mainly that there are major powers trying to impose their will, may happen conflicts, and when there are such conflicts what can be done to fix them, mainly because, due to the military and currently existing technologies, wars can mean big consequences for life on our planet, for this reason there should be sougnt solutions in the legal framework.
\end{abstract}

Keywords: Sovereignty, power, efficiency, balance, conflict. 


\section{INTRODUÇÃO}

O objetivo deste estudo foi compreender que com o avanço da tecnologia e meios de comunicação ocorreram mudanças, inclusive no direito, um exemplo dessas mudanças são a aparição dos primeiros litígios envolvendo compras via internet, muitas vezes envolvendo empresas e clientes de diferentes países.

Mas quando ocorre um litigio ou um conflito que envolve mais de um país, quem tem competência de resolver, pois cada país é um Estado, portanto possui poder para tomar decisões sem influência de outrem. Esse poder é denominado soberania, esta não é uma simples palavra dentro do ordenamento jurídico, sendo um elemento que constitui um Estado, pois se um país não possui esta soberania, se transforma em um agrupamento de pessoas que falam a mesma língua e possuem costumes parecidos.

O ponto principal deste estudo foi o que é a soberania e a busca por seu equilíbrio, uma igualdade de poder mundial, pois as leis existentes pregam que todos são iguais, que todos Estados a possuem, porém na prática, os países que são mais desenvolvidos conseguem não apenas influenciar como também controlar os demais, e mesmo existindo órgãos que surgiram para evitar conflitos e resolve-los podem não ser eficazes, principalmente quando envolve os EUA, pois este Estado é uma superpotência que tenta impor suas vontades indepentemente da vontade e decisão de outrem, utilizando como justificativa combate ao tráfico de drogas ou a segurança interna.

Ou seja, o objetivo desse estudo foi apresentar em uma linguagem que até mesmo leigos do direito conseguem entender, o que é soberania e reconhece-la como um poder e forca que constitui um Estado.

\section{METODOLOGIA}

A metodologia realizada neste trabalho surge do método hipotético-dedutivo, possuindo como origem a lei, os tratados e convenções, a doutrina e a jurisprudência.

\section{RESULTADOS}

Segundo o dicionário soberania é autoridade suprema, poder político de um Estado que não está submetido a nenhum organismo (dicionário de língua portuguesa melhoramentos, 2004), porém no direito pode significar além desse poder, uma soberania do direito, sendo o Estado uma manifestação originária desse poder (Solon, Ari Marcelo. pág. 46, 1997).

Cada Estado possui sua própria soberania independente de tamanho ou população, sendo caracterizada por ser una, indivisível e inalienável (Dallari, Dalmo de Abreu, 31ㅇe edição, pág. 87, 2012) e sendo também um dos fundamentos da constituição brasileira (art. 10, Constituição Federal de 1988), que assim determina:

Art. 1ㅇ A República Federativa do Brasil, formada pela união indissolúvel dos Estados e Municípios e do Distrito Federal, constitui-se em Estado Democrático de Direito e tem como fundamentos: I - a soberania; II - a cidadania; III - a dignidade da pessoa humana; IV - os valores sociais do trabalho e da livre iniciativa; $V$ - o pluralismo político.

Há uma percepção que esse poder, principalmente, se possui efeitos internacionais, está concentrado em países que possuem maior força, como poder de fogo (poderio militar). Também se percebe mais distintamente nos países que possuem maior poder econômico ou nos países que possuem maior poder ideológico, sendo esse poder aquele relacionado as "formas de saber, doutrinas, conhecimentos, as vezes apenas informações, ou de códigos de conduta, para exercer uma influência sobre o comportamento alheio e induzir membros do grupo a realizar ou não realizar uma ação" (Bobbio, Norberto, pág. 82-83 18 reimpressão, 2012). Todos esses poderes 
são capazes de influenciar, mesmo não existindo soberanias mais fracas nem mais fortes, há a supremacia do mais forte, pois é inegável que os EUA, URSS (observar dissolução da União Soviética em idos de 1991; hoje a supremacia é da Rússia), Europa Ocidental e Japão imponham ou já impuseram essa supremacia (Litrento, Oliveiros. Pág. 84, 1991). Atualmente, pode-se nomear como soberania dominante a dos Estados Unidos, pois ao observar não apenas sua influência na cultura (como alimentação, livros, até mesmo nas marcas de roupa) e na economia (dólar e uma das moedas de maior valor e aceita internacionalmente para cotações), influencia a soberania, as decisões de escala mundial, podendo também não existir limites, utilizando da desculpa de ameaça e luta contra o terrorismo, pois:

"[...]do ponto de vista da segurança externa dos Estados Unidos, a nova estratégia cria uma situação de insegurança coletiva e permanente, dentro do sistema mundial. O novo adversário não é, em princípio, uma religião, uma ideologia, uma nacionalidade, uma civilização ou um estado, e pode ser redefinido a cada momento pelos próprios Estados Unidos, sendo portando, variável e arbitrário. E, nesse sentido, os Estados Unidos se guardam no direito de fazer ataques preventivos contra todo e qualquer estado onde eles considerem existir bases ou apoio às ações terroristas, o que significa a auto atribuição de uma soberania imperial" (Fiori, José Luís. O Poder Global dos Estados Unidos: formação, expansão e limites.

Disponível em: http://www.poderglobal.net/wpcontent/uploads/2015/08/CAPITUALO-ESTADOS-UNIDOS-FIORI.pdf acesso em: 06 de agosto de 2016).

Ou seja, com uma "desculpa" de luta contra o terrorismo ou proteção, pode intervir em outros Estados, lesando a soberania existente, pois não se mede soberania pelo poder militar e armas de destruição em massa e sim por ser um poder existente e soberano de cada país sem exceção, não sendo apenas garantias constitucionais e uma particularidade que transforma um conjunto de pessoas em um Estado com leis e poderes para decidir.

Não obstante, há a igualdade jurídica de soberanias, reconhecida pelo Direito Público Internacional. Pode-se observar que há princípios que garantem essa igualdade, como por exemplo o princípio da igualdade soberana citado no art. 78 da Carta das Nações Unidas (O sistema de tutela não será aplicado a territórios que se tenham tornado Membros das Nações Unidas, cujas relações mútuas deverão basear-se no respeito ao princípio da igualdade soberana). Porém, esta igualdade ainda se encontra em desenvolvimento, pois por existir essa influência de Estados que se destacam no cenário mundial como potências, isso muitas vezes pode gerar conflitos.

\section{DISCUSSÃO}

"Todo Estado existe ao lado de outros Estados em uma sociedade de Estados" (Bobbio, Norberto. Pág. 101, 18a reimpressão, 2012), que possuem leis e costumes diferentes, que por terem o poder que possuem, podem entrar em conflito. Mas quando esse choque ocorre e há leis internas como no caso do Código Penal brasileiro em seus arts. 5o e 7으, que tratam da extraterritoridade e territorialidade no caso de crimes:

Art. 5o - Aplica-se a lei brasileira, sem prejuízo de convenções, tratados e regras de direito internacional, ao crime cometido no território nacional.

Art. 7o - Ficam sujeitos à lei brasileira, embora cometidos no estrangeiro:

I - os crimes:

a) contra a vida ou a liberdade do Presidente da República; 
b) contra o patrimônio ou a fé pública da União, do Distrito Federal, de Estado, de Território, de Município, de empresa pública, sociedade de economia mista, autarquia ou fundação instituída pelo Poder Público;

c) contra a administração pública, por quem está a seu serviço;

d) de genocídio, quando o agente for brasileiro ou domiciliado no Brasil; II - os crimes:

a) que, por tratado ou convenção, o Brasil se obrigou a reprimir;

b) praticados por brasileiro;

c) praticados em aeronaves ou embarcações brasileiras, mercantes ou de propriedade privada, quando em território estrangeiro e aí não sejam julgados.

Quando estes conflitos ocorrem qual é o correto? Qual Estado deverá tomar a decisão que deverá ser seguida, pois se está em suas leis internas ambos estarão corretos, pois ambos possuem soberania e poder para decidir o melhor para si.

Para tentar resolver esses conflitos além das leis internas existentes, existem os tratados e as convenções internacionais, que regulam questões relacionadas a todos os ramos do direito, abordando principalmente temas relacionados com os direitos humanos. Como a Convenção de Viena sobre o Direito dos Tratados, concluída em 23 de maio de 1969 que define tratado "significando um acordo internacional concluído por escrito entre Estados e regido pelo Direito Internacional, quer conste de um instrumento único, quer de dois ou mais instrumentos conexos, qualquer que seja sua denominação específica" (promulgado pelo Decreto no 7.030 , de 14 de dezembro de 2009.). No Brasil esses tratados podem chegar a ser equivalentes a emendas constitucionais. Emenda Constitucional no 45, de 30 dezembro de 2004

Por existir o que podemos chamar de "imperfeição jurídica" (Dallari, Dalmo de Abreu. Página 259,2012 310 edição) e para evitar grandes conflitos como as guerras mundiais surgiram organizações mundiais, como por exemplo a O.N.U (Organização das Nações Unidas), tendo como objetivo além da paz mundial, a resolução de conflitos buscando a justiça no lugar da força, a segurança internacional, a cooperação entre Estados, dentre outros propósitos.

A lei dessa organização, pode ser considerada uma constituição, chamando-se Carta das Nações Unidas que traz em seu preâmbulo alguns desses objetivos,

"Nós, os povos das Nações Unidas a preservar as gerações vindouras do flagelo da guerra, que por duas vezes, no espaço da nossa vida, trouxe sofrimentos indizíveis à humanidade, e a reafirmar a fé nos direitos fundamentais do homem, na dignidade e no valor do ser humano, na igualdade de direito dos homens e das mulheres, assim como das nações grandes e pequenas, e a estabelecer condições sob as quais a justiça e o respeito às obrigações decorrentes de tratados e de outras fontes do direito internacional possam ser mantidos, e a promover o progresso social e melhores condições de vida dentro de uma liberdade ampla. E para tais fins, praticar a tolerância e viver em paz, uns com os outros, como bons vizinhos, e unir as nossas forças para manter a paz e a segurança internacionais, e a garantir, pela aceitação de princípios e a instituição dos métodos, que a força armada não será usada a não ser no interesse comum, a empregar um mecanismo internacional para promover o progresso econômico e social de todos os povos. Resolvemos conjugar nossos esforços para a consecução desses objetivos. Em vista disso, nossos respectivos Governos, por intermédio de representantes reunidos na cidade de São Francisco, depois de exibirem seus plenos poderes, que 
foram achados em boa e devida forma, concordaram com a presente Carta das Nações Unidas e estabelecem, por meio dela, uma organização internacional que será conhecida pelo nome de Nações Unidas. " (A carta foi assinada em São Francisco, Califórnia- EUA em 26 de junho de 1945 e promulgado no Brasil pelo Decreto no 19.841 de 22 de outubro de 1945).

Além desses objetivos, pode-se observar que apresenta a busca pela prevenção de guerras mundiais (guerras no geral), pois estas foram políticas no pós segunda guerra mundial como forma de união dos povos e para evitar uma terceira guerra mundial.

A ONU possui vários órgãos fundamentais como a Assembleia Geral, o Conselho de Segurança e a Corte Internacional de Justiça, todos visando resolver conflitos e garantir a justiça e a soberania de cada Estado. No caso da Corte Internacional de justiça, pode-se recorrer a ela em todo e qualquer caso que envolva dois ou mais Estados, inclusive com os países não participantes da organização. Atualmente, a organização possui 193 membros incluindo a França, Inglaterra, Estados Unidos, Rússia, China, inclusive o Brasil, desde 1945.

\section{CONCLUSÃO}

A soberania é um poder que todo Estado possui para tomar suas próprias decisões. Todo Estado possui este poder, independentemente de qualquer característica, porém mesmo havendo leis que garantem a igualdade entre estes Estados, há fatores como o desenvolvimento militar e econômico que faz que alguns países influenciem em decisões globais, podendo até impor suas decisões, utilizando como justificativas ameaças contra sua segurança interna ou combate ao terrorismo.

Existe a busca pela igualdade do poder mundial, porem esta igualdade ainda se encontra distante, pois mesmo existindo órgãos, leis, tratados e convenções que regulam e tentam resolver os conflitos que essa desigualdade gera. Há uma pretensão de um equilíbrio do poder, porém ainda ocorrem e possivelmente ocorrerão no futuro estes conflitos. Solucionar essa desigualdade de Soberanias visa evitar conflitos futuros (devido ao poderio militar e tecnologia existentes poderia ser o fim da vida no nosso planeta).

A busca pelo equilíbrio da soberania mundial é uma busca constante, pois há grandes desigualdades principalmente sociais e econômicas, e os que são os maiores influenciadores são os países mais desenvolvidos que disseminam sua cultura e seu poder, não apenas no direito como também nos costumes mundiais, ou seja, mesmo com grandes avanços em várias áreas como comunicação, informática, tecnologia, os avanços que envolvem o direito não foram significativos, claro, surgiram leis que visam a igualdade e lutas pelos direitos humanos, mas a efetividade ainda se encontra distante. A igualdade e a resolução e prevenção de novos conflitos entre Estados são essenciais para que no futuro ocorra a garantia da efetiva soberania que está lindamente escrita nas leis, mas que não é completamente cumprida.

\section{REFERÊNCIAS}

Dallari, Dalmo de Abreu. Elementos de Teoria Geral do Estado 31ㅇe edição, Editora Saraiva, São Paulo/SP,2012.

Solon, Ari Marcelo. Teoria da Soberania como Problema da Norma Jurídica e da Decisão, Sergio Antônio Fabris Editor, Porto Alegre,1997.

Bobbio, Norberto. Estado, Governo, Sociedade: Para uma teoria geral da política. 18으 reimpressão, Editora Paz e Terra LTDA, 2012. 
Litrento, Oliveiros. A Ordem Internacional Contemporânea: Um estudo da soberania em mudança. Sergio Antônio Fabris Editor, Porto Alegre, 1991.

Fiori, José Luís. O Poder Global dos Estados Unidos: formação, expansão e limites.

Disponível em: http://www.poderglobal.net/wp-content/uploads/2015/08/CAPITUALO-ESTADOSUNIDOS-FIORI.pdf

Acesso em: 06 de agosto de 2016.

Código Penal Brasileiro de 1940.

Carta das Nações Unidas - promulgado pelo Decreto no 19.841 de 22 de outubro de 1945.

Emenda Constitucional no 45, de 30 dezembro de 2004.

Convenção de Viena sobre o Direito dos Tratados - promulgado pelo Decreto № 7.030, de 14 de dezembro de 2009.

Constituição Federal Brasileira de 1988.

MELHORAMENTOS, dicionário de língua portuguesa,2004. 